\title{
Concomitant endoscopic fundoplication - can it reduce the risk of gastroesophageal reflux following peroral endoscopic myotomy?
}

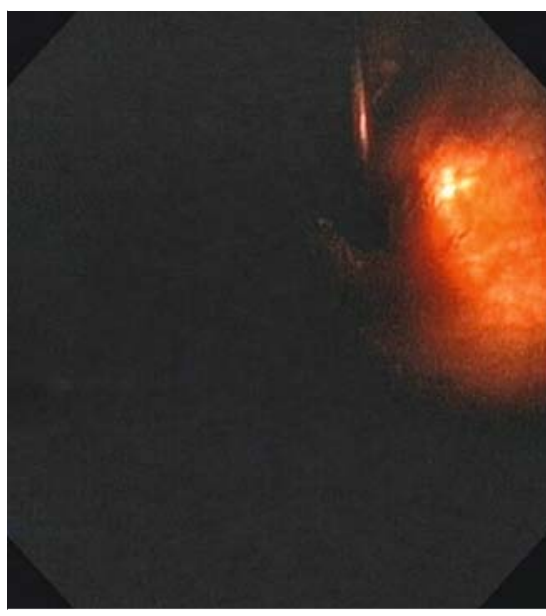

- Fig. 1 Double endoscope transillumination used to confirm that the gastroscope in the tunnel is beyond the gastroesophageal junction. The light from the ultraslim scope in the fundus is switched off and the glow of the light from the scope in the tunnel is visualized.

Gastroesophageal reflux is an emerging concern after peroral endoscopic myotomy (POEM) with a reported incidence of up to $50 \%$ [1]. Recently, a novel natural orifice transluminal endoscopic surgery (NOTES) procedure that creates an endoscopic anterior partial fundoplication $(\mathrm{POEM}+\mathrm{F})$ was reported [2]. We report on four patients with achalasia cardia treated using POEM + F.

Four patients (three women, one man; mean age 38.8 years) with type II achalasia confirmed on esophagogastroduodenoscopy (EGD) and high-resolution manometry (HRM) consented to undergo $\mathrm{POEM}+\mathrm{F}$. The mean Eckhardt score was 10 and symptom duration 9.5 months. All procedures were performed under general anesthesia. A standard anterior POEM was performed using a gastroscope (GIF-190H; Olympus Corporation, Tokyo, Japan) with a distal transparent attachment.

After completion of a full-thickness myotomy across the gastroesophageal junction, a $5.7 \mathrm{~mm}$ ultraslim gastroscope

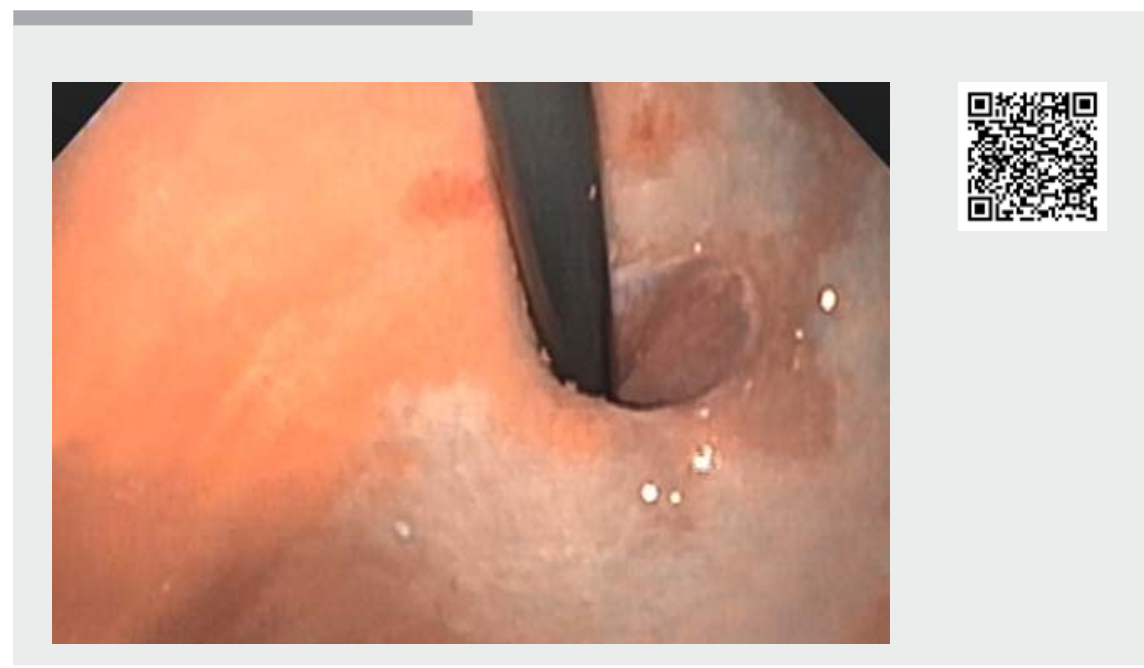

$\checkmark$ Video 1 Video illustrating the technical steps to perform a peroral endoscopic myotomy and endoscopic fundoplication (POEM $+F)$. Each step is accompanied by detailed narration describing the technical nuances of the procedure.

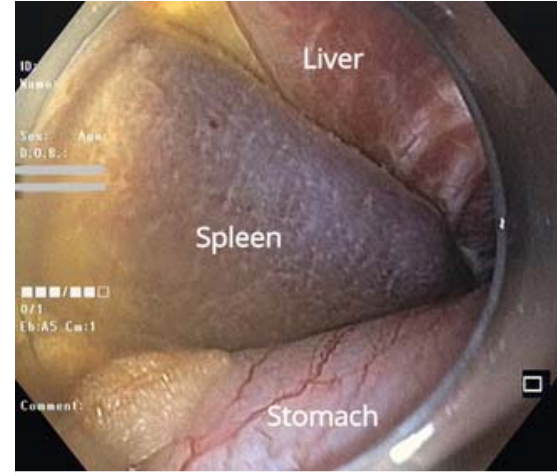

- Fig. 2 Endoscopic view of the gastric fundus from the peritoneal cavity. Note the spleen posterior to the stomach and the left lobe of liver anterior and superior to the fundus. Loose perigastric fat is also visible around the fundus. This fat contains blood vessels that may bleed if lacerated.

(GIF-190P) was introduced alongside the gastroscope into the gastric fundus. Using double-endoscope transillumination with the gastroscope in the tunnel (-Fig.1), the serosa overlying the myotomy was divided for entry into the

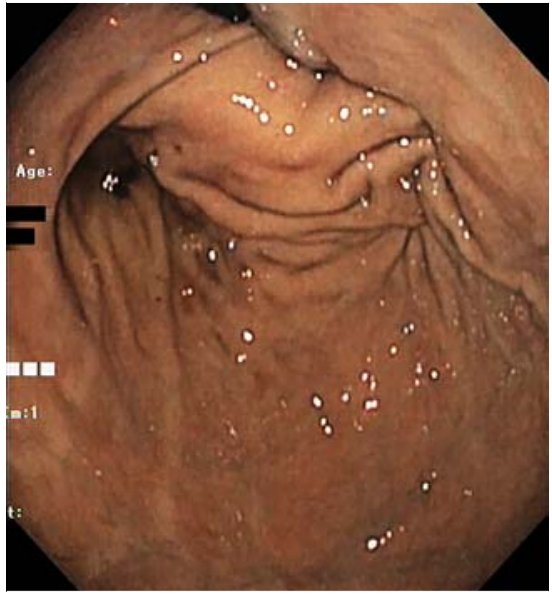

Fig. 3 Simulation of the wrap as monitored from the ultraslim endoscope in the gastric fundus. Note how the pinchcock mechanism of the lower esophageal sphincter becomes evident as the wrap forms.

peritoneal cavity. The scope was angled upward and to the left to reach the gastric fundus ( $>$ Fig. 2), which was grasped and retracted into the tunnel to create the wrap. The procedure was continuously monitored by ultraslim gastro- 


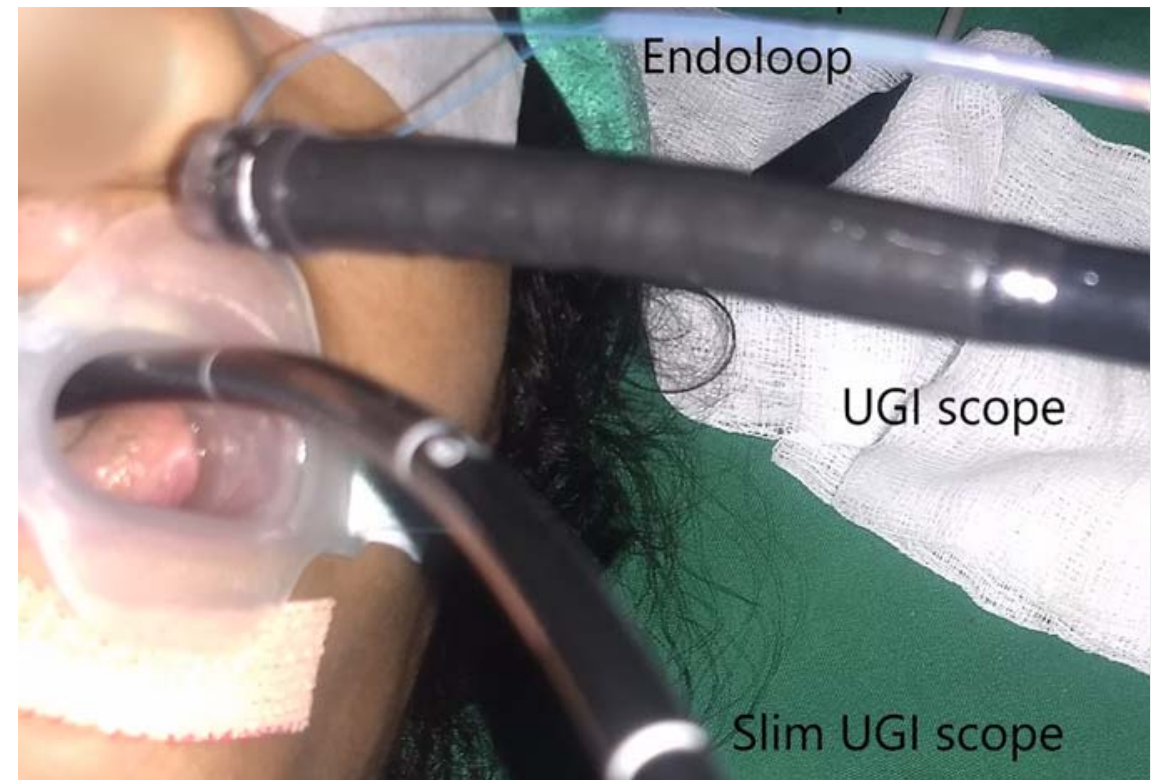

- Fig. 4 External view of the endoscope with the clip in the channel and carrying the open endoloop alongside the scope. The ultraslim endoscope is already positioned in the gastric fundus.

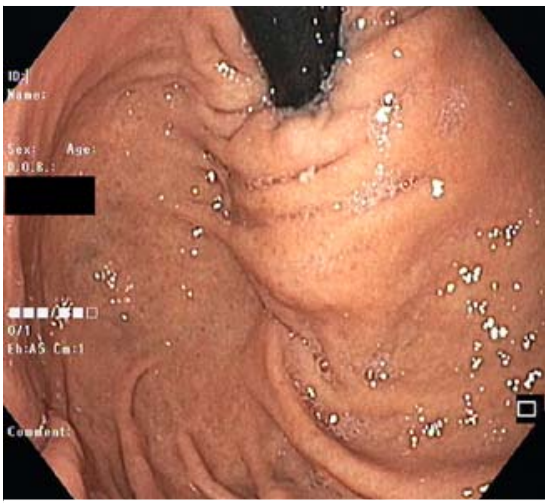

Fig. 5 Well-maintained wrap seen at one-month gastroscopy following peroral endoscopic myotomy and fundoplication.

scope (> Fig.3). Once the wrap was satisfactory, the spot on the fundic serosa was marked. The gastroscope was withdrawn from the tunnel, a $3 \mathrm{~cm}$ endoloop clasped in a reconstrainable clip was passed through the scope ( $\triangleright$ Fig.4), and the scope was reintroduced into the peritoneal cavity. The endoloop was fixed to the fundus using four clips. The gastroscope was withdrawn into the tunnel and the loop was proximally fixed to the end of the myotomy and peritoneal opening. The endoloop was tightened, the loop tail trimmed using a loop cutter, and the mucosal incision was closed ( Video 1).

After 24 hours of fasting, the patients resumed oral diet and were discharged. On follow-up at four weeks, EGD revealed an intact wrap in all patients ( Fig.5). Eckhardt scores had normalized and no patient reported symptoms of gastroesophageal reflux disease. On follow-up, $\mathrm{pH}$ studies in two of four patients confirmed the absence of abnormal acid reflux.

Endoscopy_UCTN_Code_TTT_1AO_2AJ

\section{Competing interests}

None

The authors

Amol Bapaye, Siddharth Dharamsi, Rishabh Jain, Guru Basava, Jay A. Bapaye, Rajendra Pujari, Harshal Gadhikar

Shivanand Desai Center for Digestive Disorders, Deenanath Mangeshkar Hospital and Research Center, Pune, India
Corresponding author

\section{Amol Bapaye, MD, FASGE}

Shivanand Desai Center for Digestive Disorders, Deenanath Mangeshkar Hospital and Research Center, Pune 411004,

Maharashtra, India

Fax: +91-20-49153218

amolbapaye@gmail.com

\section{References}

[1] Kumbhari V, Familiari P, Bjerregaard NC et al. Gastroesophageal reflux after peroral endoscopic myotomy: a multicenter case-control study. Endoscopy 2017; 49: 634-642

[2] Inoue H, Ueno A, Shimamura Y et al. Peroral endoscopic myotomy and fundoplication: a novel NOTES procedure. Endoscopy 2019; 51: $161-164$

\section{Bibliography}

DOI https://doi.org/10.1055/a-1000-8196

Published online: 17.9.2019

Endoscopy 2020; 52: E73-E74

(c) Georg Thieme Verlag KG

Stuttgart · New York

ISSN 0013-726X

\section{ENDOSCOPY E-VIDEOS \\ https://eref.thieme.de/e-videos}

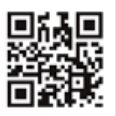

Endoscopy E-Videos is a free access online section, reporting on interesting cases and new techniques in gastroenterological endoscopy. All papers include a high quality video and all contributions are freely accessible online.

This section has its own submission website at https://mc.manuscriptcentral.com/e-videos 